\title{
O DESENVOLVIMENTO TURÍSTICO DE FOZ DO IGUAÇU A PARTIR DOS PROCESSOS DE PLANEJAMENTO URBANOS E TURÍSTICOS
}

\section{Resumo}

Thays Cristina Domareski Ruiz Universidade Federal do Paraná. Curitiba thaysdomareski@gmail.com

Eduardo Baptista Lopes Universidade do Vale do Itajaí. Balneário Camboriú edulhs@gmail.com

Francisco Antonio dos Anjos Universidade do Vale do Itajaí. Balneário Camboriú fsanjos@terra.com.br

Objetivo: O artigo tem por objetivo analisar o processo de desenvolvimento turístico de Foz do Iguaçu a partir dos processos de planejamento urbano e turístico do município, por meio da análise do seu Plano Diretor.

Método: A pesquisa caracteriza-se por ser um estudo de caso analisado a partir de pesquisas exploratórias e descritivas, de abordagem qualitativa, utilizando-se do modelo Sistêmico Territorial Turístico de Anjos (2004), que aborda temas como os sistemas fixos construídos e naturais, além de fluxos sociais e econômicos do destino.

Originalidade/Relevância: Esta pesquisa se justifica pela ausência de estudos analisando o Plano Diretor e sua relação com o planejamento urbano e turístico. No contexto do turismo brasileiro, Foz do Iguaçu é um destino turístico importante, que mais recebe turistas internacionais, onde a compreensão dos efeitos do Plano Diretor nos resultados de desenvolvimento turístico podem indicar caminhos para uma revisão/atualização do próprio Plano Diretor.

Resultados: Através da análise dos dados coletados, podem ser observados dois setores econômicos fundamentais para o processo de desenvolvimento do destino turístico de Foz do Iguaçu. Por um lado a exploração turística do Parque Nacional do Iguaçu, e por outro a exploração turística da hidrelétrica de Itaipu, responsável pela geração de energia elétrica. Ainda é possível notar o fortalecimento de áreas de caráter turístico por iniciativa da esfera pública, através da definição de zonas específicas para o desenvolvimento turístico pelo Plano Diretor Municipal.

Contribuições teóricas/metodológicas: A pesquisa evidencia a relação entre urbanismo e turismo através da análise do Plano Diretor de Foz do Iguaçu, demonstrando a importância do planejamento urbano estar vinculado e integrado ao planejamento turístico, como forma de desenvolver a cidade como um todo.

Palavras-Chave: Turismo. Planejamento. Plano Diretor. Foz do Iguaçu.

\section{Cite como}

American Psychological Association (APA)

Domareski-Ruiz, T, C., Lopes, E. B., \& Anjos, F. A dos. (2020). O desenvolvimento turístico de Foz do Iguaçu a partir dos processos de planejamento urbanos e turísticos. PODIUM Sport, Leisure and Tourism Review, São Paulo, 9(1), 1-20. https://doi.org/10.5585/podium.v9i1.17480. 


\title{
THE TOURISM DEVELOPMENT OF FOZ DO IGUAÇU FROM URBAN AND TOURISM PLANNING PROCESSES
}

\begin{abstract}
Objective: The paper aims to analyze the tourism development process of Foz do Iguaçu from the urban and tourism planning processes of the municipality, through the analysis of its Master Plan.
\end{abstract}

Methodology/ Approach: The research is characterized by being a case study analyzed from exploratory and descriptive research, with a qualitative approach, using the Anjos Turistic Systemic Territorial model (2004), which addresses themes such as the built and natural fixed systems, in addition to destination's social and economic flows.

Originality/ Relevance: This research is justified by the absence of studies analyzing the Master Plan and its relationship with urban and tourism planning. In the context of Brazilian tourism, Foz do Iguaçu is an important tourist destination, which receives more international tourists, where the understanding of the effects of the Master Plan on tourism development results may indicate ways for a review / update of the Master Plan itself.

Main Results: Through the analysis of the collected data, two fundamental economic sectors for the development process of the tourist destination of Foz do Iguaçu can be observed. On the one hand, the touristic exploration of the Iguaçu National Park, and on the other, the touristic exploration of the Itaipu hydroelectric plant, responsible for the generation of electric energy. It is still possible to note the strengthening of areas of a tourist nature by initiative of the public sphere, through the definition of specific zones for tourism development by the Municipal Master Plan.

Theoretical/ Methodological contributions: The research highlights the relationship between urbanism and tourism through the analysis of the Foz do Iguaçu Master Plan, demonstrating the importance of urban planning being linked and integrated with tourism planning, as a way to develop the city as a whole.

Key-Words: Tourism. Planning. Master plan. Foz do Iguaçu.

\section{EL DESARROLLO TURÍSTICO DE FOZ DO IGUAÇU DESDE LOS PROCESOS DE PLANIFICACIÓN URBANA Y TUUÍSTICA}

\section{Resumen}

Proposito del estudio: El artículo tiene como objetivo analizar el proceso de desarrollo turístico de Foz de Iguazú a partir de los procesos de planificación urbana y turística del municipio, a través del análisis de su Plan Maestro.

Metodología/ enfoque: La investigación se caracteriza por ser un estudio de caso analizado a partir de investigación exploratoria y descriptiva, con un enfoque cualitativo, utilizando el modelo territorial sistémico turístico Anjos (2004), que aborda temas como los sistemas fijos construidos y naturales, además de flujos sociales y económicos del destino. 
Originalidad/ Relevancia: Esta investigación se justifica por la ausencia de estudios que analicen el Plan Maestro y su relación con la planificación urbana y turística. En el contexto del turismo brasileño, Foz do Iguaçu es un importante destino turístico, que recibe más turistas internacionales, donde la comprensión de los efectos del Plan Maestro en los resultados del desarrollo turístico puede indicar formas de una revisión / actualización del Plan Maestro en sí.

Resultados Principales: A través del análisis de los datos recopilados, se pueden observar dos sectores económicos fundamentales para el proceso de desarrollo del destino turístico de Foz de Iguazú. Por un lado, la exploración turística del Parque Nacional Iguazú, y por otro, la exploración turística de la central hidroeléctrica de Itaipú, responsable de la generación de energía eléctrica. Todavía es posible notar el fortalecimiento de áreas de naturaleza turística por iniciativa de la esfera pública, a través de la definición de zonas específicas para el desarrollo turístico por parte del Plan Maestro Municipal.

Contribuiciones teóricas/ metodológicas: La investigación destaca la relación entre urbanismo y turismo a través del análisis del Plan Maestro de Foz do Iguaçu, demostrando la importancia de que la planificación urbana esté vinculada e integrada con la planificación turística, como una forma de desarrollar la ciudad en su conjunto.

Palavras-clave: Turismo. Planificación. Plan Maestro. Foz do Iguaçu.

\section{Introdução}

O turismo como uma das indústrias de desenvolvimento mais rápido do mundo obriga as organizações de gestão de destino a buscar estratégias e soluções ambiciosas para atrair uma parcela cada vez maior de turistas para seu destino (Hankinson, 2010).

Neste sentido, o setor de turismo desempenha uma importante função enquanto motor de desenvolvimento, alcançando benefícios consideráveis para o país, estado ou região, transformando-se em um dos mais importantes campos de estudo frente ao fenômeno da globalização, reunindo dimensões econômicas, políticas, sociais e ambientais. O crescimento do interesse no planejamento e na gestão de destinos turísticos reflete uma preocupação não só pelo desenvolvimento do turismo, mas também pela necessidade de gerenciá-lo para garantir que os destinos sejam sustentáveis e competitivos (Pearce \& Schänzel, 2013; Pearce, 2016).

Abordagens contemporâneas têm reconhecido que o sucesso de qualquer destino turístico é alcançado quando as perspectivas da comunidade local são consideradas no processo de planejamento, e essa relação se tornou um elemento chave no planejamento turístico. Por outro lado, as políticas e o planejamento para destinos turísticos foram amplamente fundamentados teoricamente em modelos evolutivos dos anos 70 e 80, o que direciona o gerenciamento do destino turístico (Chen, Thapa, Kim \& Yi, 2017).

Nos estudos de turismo, o destino turístico pode ser analisado sob diversas perspectivas (Saraniemi \& Kylanen, 2011). O turismo se caracteriza por sua grande complexidade, não só pela grande quantidade de elementos e atores envolvidos, mas também pelos diferentes setores econômicos do seu desenvolvimento (Saraniemi \& Kylanen, 2011; Organização Mundial de Turismo [OMT], 2015) e representa um visível impacto econômico no destino turístico, podendo se caracterizar como parte do desenvolvimento tanto no nível local, como nacional, que se planejado, pode ser realizado de forma sustentável (Dias, 2003).

O planejamento pode ser entendido como um processo atuante de tomada de decisão, baseado no passado e presente (Hall, 2001), evidencia-se a necessidade de atuar com o processo 
de planejamento no destino turístico, onde se presume que um processo dirigido da forma correta deve resultar na ampliação dos aspectos positivos e minimização dos aspectos negativos.

Neste estudo será abordado o destino turístico de Foz do Iguaçu, sob as temáticas do planejamento e gestão do turismo. A cidade de Foz do Iguaçu está estrategicamente localizada no extremo oeste do estado do Paraná, na fronteira natural entre Brasil, Argentina (Puerto Iguazu) e o Paraguai (Ciudad del Este), sendo a cidade com maior população de fronteira do Brasil com 263.915 habitantes Instituto Brasileiro de Geografia e Estatística (IBGE) (2016). Foz do Iguaçu é ainda reconhecida como um destino importante para o turismo no Brasil, configurando-se historicamente como um dos principais portões de entrada de turistas no país, principalmente internacionais (Foz Do Iguaçu, 2017).

Observando Foz do Iguaçu, como destino turístico tem-se uma caracterização passível de discutir o sistema turístico do destino internacional, norteado por dois atrativos principais (Cataratas do Iguaçu e a Itaipu Binacional) que compõe a oferta e toda história da cidade, assim como, oferecem elementos sobre a complexidade do processo de desenvolvimento instalado no destino a ser abordado (Domareski, 2011). O artigo tem por objetivo analisar o processo de desenvolvimento turístico de Foz do Iguaçu a partir dos processos de Planejamento Urbanos e Turísticos do Município.

\section{Planejamento e gestão do destino turístico}

O turismo é apresentado como um setor capaz de promover a aceleração econômica e o incremento nas áreas social, cultural e ambiental. No entanto, a opção pelo desenvolvimento por meio do turismo é mais complexa do que parece, pois, além de ser uma atividade multissetorial, que envolve diversos atores, traz, com o seu desenvolvimento, diversos impactos, positivos e negativos (Crouch \& Ritchie, 1999), necessitando, assim, de planejamento para que se sustente ao longo do tempo.

O planejamento é um instrumento importante de ação dos governos em todos os níveis, para promover o desenvolvimento econômico, dentro de uma lógica sustentável. Faz parte das principais atividades econômicas mundiais, como etapa fundamental do processo de desenvolvimento de uma localidade. Um planejamento estratégico baseado em desenvolvimento sustentável é uma forma de minimizar os impactos negativos e ajudar a uma distribuição social e econômica dos benefícios gerados (Ruschmann, 1997; Hall, 2004; Mccartney, 2008).

Desta maneira, é possível afirmar que o planejamento surge como forma de administrar os recursos do Estado e da iniciativa privada para alcançar objetivos e metas, estabelecidos previamente de forma mais simples, e consequentemente para gerar bem-estar à comunidade. O planejamento, portanto, está envolvido em todas as esferas, seja numa simples decisão até as mais complexas e segue como um meio de observação de variáveis que em análise traduzem a possibilidade de desenvolvimento e crescimento de uma localidade.

O planejamento é a identificação de fatores competitivos de mercado e potencial interno, para atingir metas e planos de ação que resultem em vantagem competitiva para o destino turístico, e pode ser considerada uma ferramenta de gestão de destinos turísticos. A gestão eficiente do destino turístico, a partir de uma abordagem mais holística, de acordo com as especificidades locais, se torna mais dinâmica e ágil (Pearce, 2015). Onde sem este instrumento, os objetivos, metas e diretrizes de desenvolvimento não estão claros, podendo levar o projeto à total inviabilidade (Lohmann \& Netto, 2008) da prática da atividade turística, não alcançando os objetivos inicialmente propostos. O planejamento turístico pode ser realizado de diversas 
maneiras, podendo ser aplicado por múltiplas teorias, pois é uma prática que visa à organização e/ou ordenação, no caso do turismo para chegar ao crescimento desejado de forma satisfatória.

Antes de ser uma ação técnica, o planejamento é uma ação política. Assim, as relações de poder existentes devem ser bem analisadas, uma vez que suas consequências no processo de planejamento podem ser decisivas. Como forma de atingir metas determinadas, o planejamento é uma ação que resulta na formulação de objetivos e propostas de forma concreta, constante e permanente, e que deve ser considerado como um elemento crítico para se garantir o desenvolvimento dos destinos turísticos (Hall, 2004).

Neste contexto, o plano diretor, no planejamento de uma cidade turística, é um elemento essencial para a construção do planejamento turístico. O Estatuto da cidade define o plano como um conjunto de princípios e regras orientadoras da ação dos agentes que constroem e utilizam o espaço urbano (Brasil, 2002, p. 40). Ele organiza o crescimento e o funcionamento do município. No que tange o plano diretor, adota-se o conceito de que se constitui em um [...] conjunto de normas obrigatórias, elaborado por lei municipal específica, integrando o processo de planejamento municipal, que regula as atividades e empreendimentos do próprio Poder Público Municipal e das pessoas físicas ou jurídicas, de direito privado ou público, a serem levadas a efeito no território municipal (Machado, 2012, p. 380).

Os princípios que norteiam o plano diretor estão contidos no Estatuto da Cidade, onde esse plano está definido como instrumento básico para orientar a política de desenvolvimento e de ordenamento da expansão urbana do município. É obrigatório para os municípios: com mais de 20 mil habitantes; integrantes de regiões metropolitanas e aglomerações urbanas; com áreas de especial interesse turístico; situados em áreas de influência de empreendimentos ou atividades com significativo impacto ambiental na região ou no país. O plano diretor se apresenta como um instrumento básico do planejamento urbano nacional. A sua valorização, observada nos anos 1990 e 2000 têm norteado uma política urbana nacional (Rezende \& Ultramari, 2007).

Como afirma Vieira (2011, p. 20), cabe ao Estado primar pelo planejamento e por todos os outros fatores essenciais ao desenvolvimento do turismo, em cooperação com a iniciativa privada com o objetivo de alcançar o desenvolvimento sustentável das atividades turísticas. Segundo Hall (2004), para que haja desenvolvimento sustentável do turismo, é preciso avaliar e monitorar as ações. Anjos (2004) ainda ressalta que o planejamento precisa ser flexível o suficiente para garantir que a gestão de cada processo aconteça de forma contínua e sistêmica, resultando em estratégias eficientes e eficazes, social, ecológica e economicamente, onde a avaliação e monitoramento são imprescindíveis.

Dessa forma, é fundamental para o processo de planejamento buscar a sustentabilidade em modelos de gestão, bem como políticas públicas coordenadas e integradas, como meio de aumentar a capacidade socioeconômica, ambiental e cultural da atividade. Além disso, é importante ressaltar que a utilização de conceitos, modelos, técnicas e instrumentos cientificamente fundamentados e adaptados ao que se vai planejar têm traduzido resultados evidentes e compensadores (Gandin, 2001, p. 82). Por consequência, ainda considera-se como uma ferramenta indispensável na gestão de destinos turísticos.

\section{Metodologia}

Este estudo se caracteriza como exploratório de abordagem qualitativa, configurado em um estudo de caso. Como a pesquisa exploratória tem por finalidade conhecer ou aprofundar conhecimentos e discussões (Barros \& Lehfeld, 2000; Malhotra, 2006), o presente estudo explorou problemas específicos de um destino turístico, a partir de critérios de análise dos fixos 
e fluxos do Sistema Territorial Turístico (Anjos, 2004), permitindo uma maior compreensão do tema investigado.

O caráter qualitativo da pesquisa permitiu a apreensão e registro de fatos e fenômenos identificados no ambiente, tendo o pesquisador como elemento chave no processo, valorizando o contato do mesmo com os processos presentes no meio, descrevendo os fatos para compreensão das complexidades relativas ao tema e objeto analisados (Godoy, 1995).

O estudo de caso é uma investigação empírica que estuda o como e o porquê de fenômenos contemporâneos. O estudo de caso ainda se constitui uma estratégia de pesquisa que requer múltiplos métodos e fontes para explorar, descrever e explicar um fenômeno em seu contexto (Yin, 2005), e justifica sua importância por reunir informações numerosas e detalhadas que possibilitem apreender a totalidade de uma situação (Bruyne, Herman \& Schoutheete, 1977; Yin, 2005).

Nesse sentido, este estudo foi conduzido em duas etapas (Quadro 1):

Quadro 1- Coleta de dados

\begin{tabular}{|c|c|c|}
\hline Etapas & Descrição & Fonte \\
\hline \multirow{4}{*}{ Etapa 01} & $\begin{array}{l}\text { - Levantamento de dados econômicos, demográficos, ambientais, espaciais } \\
\text { e sociais de Foz do Iguaçu; }\end{array}$ & \multirow{4}{*}{$\begin{array}{l}\text { Dados do } \\
\text { IBGE; } \\
\text { Plano Diretor; }\end{array}$} \\
\hline & - Levantamento de informações do Plano Diretor de $2006^{1}$; & \\
\hline & $\begin{array}{l}\text { - Os dados levantados foram enquadrados nas categorias do modelo de } \\
\text { análise: fluxos sociais e econômicos; fixos naturais e construídos, pelo } \\
\text { Sistema Territorial Turístico (Anjos, 2004); }\end{array}$ & \\
\hline & $\begin{array}{l}\text { - Reconhecimentos dos Sub-Sistemas territoriais Turísticos de Foz do } \\
\text { Iguaçu; }\end{array}$ & \\
\hline \multirow{2}{*}{ Etapa 02} & $\begin{array}{l}\text { - Identificação das principais metas projetadas, implantadas e gerenciadas } \\
\text { pelo poder público municipal entre } 2006 \text { e } 2018 \text {; }\end{array}$ & \multirow{2}{*}{$\begin{array}{c}\text { Relatórios do } \\
\text { Iguassu } \\
\text { Convention \& } \\
\text { Visitors } \\
\text { Bureaux; }\end{array}$} \\
\hline & $\begin{array}{l}\text { - Análise da relação das metas do plano diretor com as Zonas Urbanas da } \\
\text { Cidade e a Formação dos Sub-sistemas Turísticos; }\end{array}$ & \\
\hline
\end{tabular}

Fonte: Elaboração própria, 2019.

Para esta análise será utilizado o Sistema Territorial Turístico (Anjos, 2004). O sistema turístico de um destino pode ser dividido em dois grupos de usuários, ou também podemos chamar de dois grandes grupos sócio-territoriais, que são seus os principais constituintes: os turistas e os residentes, e também pelas dimensões de sua estrutura, em quatro subsistemas, dois materializados (fixos) e dois imateriais (fluxos): ambiente natural, ambiente construído, dinâmicas sociais e dinâmicas econômicas (Anjos, Anjos \& Oliveira, 2013).

Anjos (2004) afirma que, para a compreensão do sistema territorial turístico, devem ser consideradas as especificidades territoriais de dois subsistemas sociais que o constituem: o subsistema relacionado com os residentes e o subsistema relacionado com os turistas. Cada subsistema tem alguns interesses convergentes e outros antagônicos. Assim, cada subsistema deve ser analisado em sua particularidade e em suas relações, buscando reconhecer as especificidades, dinâmicas e sobreposições (de escalas espaciais e temporais) entre os dois subsistemas (Figura 01). E para, de fato compreender essa relação entre fixos e fluxos, residentes e turistas é necessário analisá-los no contexto amplo do planejamento, buscando o equilíbrio dessas relações. Ao observar a figura, é possível perceber que a análise do espaço turístico para o planejamento, precisa, em determinado momento, unir os subsistemas de fixos e dos fluxos.

\footnotetext{
${ }^{1}$ Até a revisão final deste estudo, ainda não havia sido lançado o novo Plano Diretor do município.
} 
Figura 1 - Sistema Territorial Turístico

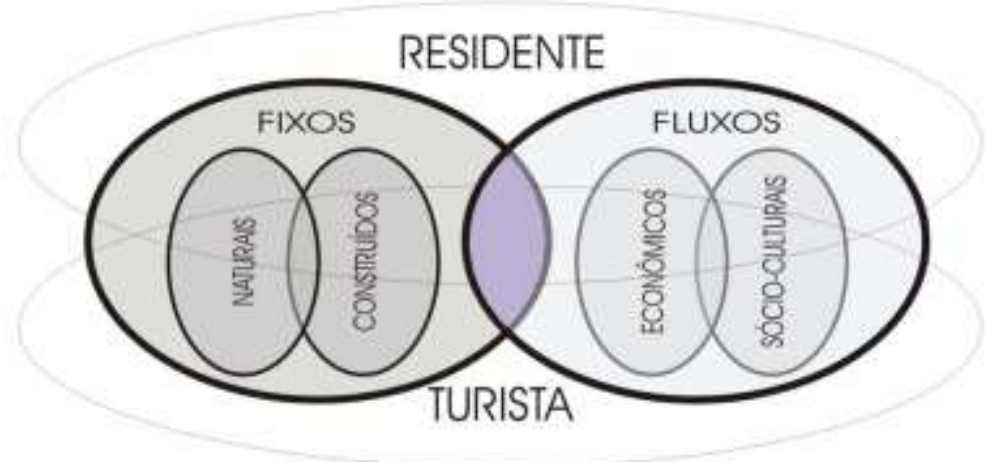

Fonte: Anjos, 2004.

O subsistema de fixos naturais é composto pelos elementos naturais, cujas dinâmicas são resultantes de processos ecológicos integrantes do sistema natural, e controlados por dinâmicas não humanas, e os fixos construídos são resultantes das ações humanas sobre os espaços. Já o subsistema dos fluxos compreende as dinâmicas socioculturais, que envolvem a relação do homem com os sistemas ecológicos, econômicos e o próprio sistema social, bem como as dinâmicas econômicas, que são compostas por dinâmicas relacionadas à produção, distribuição, consumo e acumulação do capital. Esse subsistema é formado por um conjunto de organizações que atuam, para atender, ora o residente, ora o próprio turista (Anjos, 2004). Evidencia-se ainda, que os elementos fixos permitem relações que modifiquem o próprio lugar e os fluxos recriam as condições ambientais, sociais e redefinem cada lugar (Santos, 1997).

$\mathrm{Na}$ organização da pesquisa foi realizada a identificação e o reconhecimento dos sistemas ecológicos, espaciais, sociais e econômicos do destino turístico. $\mathrm{Na}$ sequência, a identificação das principais metas projetadas, implantadas e gerenciadas, através do Plano Diretor que contribuíram para o processo de planejamento turístico de Foz do Iguaçu. Depois de identificados, ocorreu a etapa de análise de indicadores sociais, econômicos, espaciais (infraestrutura), político-institucionais e ecológicos do município de Foz do Iguaçu.

Dessa forma, o planejamento e a gestão precisam fundamentar as novas perspectivas do destino turístico: ambientais, econômicas, políticas e sociais, onde a visão sistêmica do planejamento territorial é um instrumento eficiente para a implantação de um sistema proposto, visando buscar a solução para problemas prioritários, relacionados com o desenvolvimento de um determinado espaço (Anjos, Anjos \& Oliveira, 2013).

\section{Resultados: Sistema Turístico de Foz do Iguaçu}

A necessidade de compreender o sistema turístico de Foz do Iguaçu surge da complexidade que envolve o destino turístico, assim sendo, fez-se esta delimitação em subsistemas para melhor compreender e analisar a gestão do destino.

A região turística da tríplice fronteira, onde Foz do Iguaçu está inserida é composta por mais duas cidades, Ciudad Del Este (Paraguai) e Puerto Iguazu (Argentina) e concentra uma população de aproximadamente setecentos mil habitantes (Domareski, 2011; Foz Do Iguaçu, 2015). A localização estratégica de Foz do Iguaçu é fator de primordial importância neste contexto. Se observado num contexto regional mais amplo, identificam-se três subsistemas, cada qual representado por um município, e que apresentam relações de interdependência. 
Porém, este trabalho abordará apenas o sistema turístico de Foz do Iguaçu, que apresenta a atividade turística mais consolidada. Considerando o sistema turístico de Foz do Iguaçu, podem ser observados dois subsistemas, que serão denominados de Subsistema Turismo-Compras e de Subsistema Turismo-Cataratas. É necessário entender que o sistema pode ser compreendido como um conjunto de elementos que interagem entre si, no ambiente interno ou externo, a exigência é que eles funcionem por conta própria.

Este recorte foi determinado a partir do ponto de vista socioeconômico, no contexto do destino turístico. Do ponto de vista social, onde foi levado em consideração o perfil do turista, e econômico, por se tratar de uma região representativa financeiramente. Neste sistema, serão analisadas as vertentes: social, econômica, e ambiental do território de Foz do Iguaçu - Paraná - Brasil.

\subsection{Sistema dos Fixos Naturais}

Os sistemas territoriais em estudo, o destino turístico de Foz do Iguaçu, serão apresentados seguindo o modelo de Anjos (2004), dessa forma, centrados nos recursos naturais que compõe o sistema de fixos naturais que compreendem os elementos naturais que interagem no sistema do destino turístico, sendo caracterizados o relevo, fauna, vegetação, hidrografia e clima.

Foz do Iguaçu está localizada no extremo oeste do Estado do Paraná, no terceiro planalto paranaense, na fronteira com a Argentina (Puerto Iguazu) e o Paraguai (Ciudad Del Este). Seu relevo apresenta encostas levemente onduladas com altitude média de 192 metros, com solos de textura argilosa, de origem eruptiva, profundos e ricos em matéria orgânica. A oeste do município corre o rio Paraná, ao sul o rio Iguaçu, ao norte fica o Lago de Itaipu e a sudeste o Parque Nacional do Iguaçu ${ }^{2}$, uma das últimas reservas de mata nativa intacta que existem no Paraná. No sudoeste de Foz os Rios Iguaçu e Paraná se unem formando a tríplice fronteira entre Brasil, Argentina e Paraguai. O destino turístico de Foz do Iguaçu, através do PNI, abriga grande diversidade de espécies animais sob proteção da legislação federal, muitas delas vulneráveis ou ameaçadas de extinção. O município é limitado pelos dois maiores rios do Estado: Paraná ${ }^{3}$ e Iguaçu ${ }^{4}$, que fazem parte da Bacia do Prata. Os rios Iguaçu e Paraná desempenham, paralelamente, importantes papéis no desenvolvimento municipal, o rio Iguaçu, pelo elevado interesse turístico, e o Paraná ${ }^{6}$, pelo seu potencial hidrelétrico (Foz Do Iguaçu, 2015).

A cidade de Foz do Iguaçu está estrategicamente inserida num contexto geográfico onde suas potencialidades naturais, como a presença do Rio Paraná e do Rio Iguaçu e a presença das Cataratas são exploradas sobremaneira. O destino se aproveita da presença dessas formações geográficas para desenvolver a geração de energia (Itaipu) e para visitação (Itaipu e Cataratas).

É reconhecido e caracterizado internacionalmente pelas Cataratas do Iguaçu. É importante, neste contexto, ponderar que apesar de cumprir a função bem definida, a construção da Usina Hidrelétrica de Itaipu, trouxe efeitos decorrentes de uma construção desta magnitude. No passado era citada pelo notável salto no crescimento econômico. Atualmente é apontada

\footnotetext{
${ }^{2}$ Parque Nacional do Iguaçu será referenciado como PNI.

${ }^{3} \mathrm{O}$ rio Paraná possui cerca de $4.900 \mathrm{~km}^{2}$ de extensão, sendo o segundo em comprimento da América do Sul. Representa trecho da fronteira entre Brasil e Paraguai, onde foi implantada a usina hidrelétrica Itaipu Binacional e posteriormente, faz fronteira entre o Paraguai e a Argentina.

${ }^{4} \mathrm{O}$ rio Iguaçu é o maior rio totalmente paranaense. Nasce próximo da Serra do Mar, na junção dos dois rios Ivaí e Palmital, no limite dos municípios de Pinhais, São José dos Pinhais e Curitiba. Depois de chegar às Cataratas, o rio Iguaçu segue seu rumo até sua foz ao encontrar o rio Paraná, formando a tríplice fronteira.

${ }^{5}$ Onde está localizada as Cataratas do Iguaçu.

${ }^{6}$ Onde está localizada a Itaipu Binacional.
} 
como o segundo atrativo turístico no destino de Foz do Iguaçu pela estrutura turística que oferece. Do ponto de vista dos estudos do turismo é preciso ressaltar os subprodutos turísticos criados pela Itaipu Binacional: Centro de Recepção dos Visitantes, Ecomuseu de Itaipu, Refúgio Biológico Bela Vista e a Iluminação Monumental de Itaipu, todos os espaços administrados diretamente pela entidade (Foz Do Iguaçu, 2015).

\subsection{Sistema de Fixos Construídos}

Os elementos que constituem o sistema de fixos construídos são aqueles elementos construídos pelo homem, como os equipamentos e toda a infraestrutura urbana e de acesso, representados pela rede viária, rede de água, esgoto, energia elétrica, equipamentos construídos e espaços de lazer.

O acesso a Foz do Iguaçu pode ser efetuado pelo Brasil, pelo Paraguai e pela Argentina, devido à sua localização favorável, na tríplice fronteira. $\mathrm{O}$ acesso brasileiro pode ser feito de duas maneiras: pela BR-277 ou pelo Aeroporto Internacional de Foz do Iguaçu. A BR-277 foi inaugurada em março de 1969, e tem 730 km de extensão, com início no Porto de Paranaguá e término na Ponte da Amizade, em Foz do Iguaçu.

No caso do acesso pelo aeroporto, a Empresa Brasileira de Infraestrutura Aeroportuária - INFRAERO - é a administradora do aeroporto desde 1974. Em 1986, fez um plano de ampliação que foi concluído em 03 de maio de 1989, dentro dos modernos padrões de operações e funcionalidade. O Aeroporto ${ }^{7}$ Internacional de Foz do Iguaçu está localizado na BR 469, km 16,5 - Rodovia das Cataratas. Durante o período de 2012 ao primeiro semestre de 2014, o Terminal de Passageiros do aeroporto passou por obras de reforma e ampliação. Foram ampliadas as salas de embarque, desembarque, saguão, check-in e estacionamento de veículos, além da implantação de novos sistemas de climatização, monitoramento eletrônico de segurança, som, informações de voos e contra incêndio. O sistema de funcionamento do aeroporto é 24 horas e dispõe de voos com destino aos principais pontos do Brasil. De acordo com os dados da Infraero (2019), operam 26 voos das cias aéreas: Azul, Gol, Latam, Avianca, Passaredo, Air Canada, Alitalia, Ethiopian Airlines, South African Airways, Tap Portugal e United Airlines.

O acesso pela Argentina pode ser feito pela Ponte Tancredo Neves que liga o Brasil à Argentina e pelo Aeropuerto Internacional del Cataratas del Iguazú, localizado na cidade fronteiriça de Puerto Iguazú. Ele se encontra a $7 \mathrm{~km}$ das Cataratas do Iguaçu e $20 \mathrm{~km}$ de Puerto Iguazú. Oferece vôos de Buenos Aires, Córdoba e Salta.

O acesso pelo Paraguai pode ser feito pela Ponte da Amizade, através da Rodovia BR277 e pelo Aeropuerto de Ciudad del Este Guaraní Internacional. É o segundo aeroporto mais importante do Paraguai. Está localizado na cidade contígua à Ciudad del Este, Minga Guazú, à $26 \mathrm{~km}$ do centro de Ciudad del Este, na fronteira com Foz do Iguaçu.

O sistema de atrativos turísticos pode ser considerado o mais representativo do destino turístico. Em Foz do Iguaçu, o principal atrativo turístico são as Cataratas do Iguaçu, localizadas no $\mathrm{PNI}^{8}$. Além disso, com outros produtos turísticos inseridos no PNI, é possível fazer esportes como o rafting, tirolesa, rapel, arvorismo, passeios de jipe e de barco. Está localizada no Sul da cidade de Foz do Iguaçu, e é acessada pela BR-469 (Rodovia das Cataratas).

\footnotetext{
${ }^{7}$ Está à $13 \mathrm{~km}$ do centro da cidade, $12 \mathrm{~km}$ das Cataratas do Iguaçu, $10 \mathrm{~km}$ da Ponte Tancredo Neves (Argentina), $20 \mathrm{~km}$ da Ponte da Amizade (Paraguai) e $30 \mathrm{~km}$ da Usina Hidrelétrica de Itaipu.

${ }^{8}$ Em 1986, foi tombado pela UNESCO como Patrimônio Mundial Natural da Humanidade, constituindo-se em uma das maiores reservas florestais da América do Sul.
} 
A Usina Hidrelétrica de Itaipu ${ }^{9}$, também possui um centro de recepção de visitantes onde é permitida uma visita panorâmica à usina, o Ecomuseu de Itaipu que conta a história da construção da usina e o Refúgio Biológico Bela Vista que é uma unidade de conservação que abriga os animais desalojados na formação do reservatório da usina, que completam o Complexo Turístico de Itaipu. Localiza-se no extremo norte da cidade, e pode ser acessado pela Avenida Tancredo Neves, que a liga diretamente ao centro da cidade.

Além disso, Foz do Iguaçu abriga um parque particular, chamado Parque das Aves, criado em 1994 e que conta atualmente com 17 hectares de mata nativa, situado próximo ao PNI. O parque abriga cerca de 1.000 aves de 150 espécies brasileiras, além de outros exemplares exóticos, sendo portanto o maior parque de aves da América Latina.

No Marco das Três Fronteiras, os rios Iguaçu e Paraná se encontram, construído na fronteira da Argentina, Brasil e Paraguai. O perfil cosmopolita e multicultural da cidade se representa em vários atrativos turísticos religiosos como o Templo Budista, a Mesquita Muçulmana e a Igreja Matriz.

E ainda, o comércio que foi estabelecido entre as duas cidades, Foz do Iguaçu e Ciudad Del Este, que não pode ser esquecido nesta configuração de desenvolvimento local, o "Turismo de Compras"10 que teve seu marco de 1980 à 1995. E em um segundo momento, o comércio com a cidade de Puerto Iguazu que se fortaleceu ao longo do tempo, destacando-se os restaurantes típicos e o comércio local, além do Duty Free (shopping com isenção de impostos), localizado ao lado da aduana argentina.

Como forma de suporte aos atrativos turísticos e consolidação do destino, aparecem os serviços de hospedagem. Considerando os hotéis mais representativos ${ }^{11}$ e seus centros de eventos, evidencia-se que sua lógica de localização obedece às infraestruturas existentes ou proximidade com os destinos turísticos. Uma aglomeração é relacionada a presença do PNI e da Rodovia das Cataratas e do aeroporto de Foz do Iguaçu (infraestruturas de acesso) onde os maiores hotéis com infraestrutura de lazer e de eventos abrigam-se. Um segundo aglomerado surge ao longo da BR-277 (infraestrutura de acesso), com grandes hotéis e centros de eventos. Por fim, um terceiro aglomerado, localizado no centro, com hotéis menores, mas de caráter de negócios, por vezes de cadeias internacionais, como o Mercure.

Em síntese, em 1990, os atrativos bases eram as Cataratas do Iguaçu e compras no Paraguai, e com o desenvolvimento do destino turístico, outros segmentos foram ocupando espaço na localidade. Em 1995, o turismo de compras atinge seu auge, colaborando com as exportações diretamente no setor econômico da cidade. Em 2000, surge a necessidade de inovar e trazer novos atrativos ao destino, além de reformas e revitalizações nos atrativos turísticos já existentes. De 2005 à 2019 novos produtos e subprodutos turísticos dentro dos atrativos foram criados a fim de oferecer mais opções aos visitantes e aumentar a taxa de permanência no destino.

Em 2014 chega em Foz do Iguaçu o Grupo Dreamland, que inaugura o Museu de Cera e na sequência foi trazendo outras atrações, como o Vale dos Dinossauros, Maravilhas do Mundo e o Dreams Ice Bar.

No final de 2016, é concluída a primeira etapa da revitalização do Marcos das Três Fronteiras, onde o projeto Marco das Américas assenta no conceito de integração entre povos e culturas. O objetivo constituir uma área de entretenimento histórico-cultural, superando a ideia de um parque turístico tradicional. Para tanto, o complexo celebra a convergência cultural da região fazendo alusão às Reduções Jesuítico-Guaranis, processo que marca a formação

\footnotetext{
${ }^{9}$ É a maior hidrelétrica do mundo em produção de energia.

10 "Turismo de Compras", termo adotado para classificar o fluxo de visitantes com foco exclusivo de compras de produtos importados em Ciudad Del Este no Paraguai, sem sua compreensão dentro do fenômeno turístico.

${ }^{11}$ Hotéis com preços a partir de $\mathrm{R} \$ 51,00$, que representam a grande maioria de leitos do destino.
} 
social, política e cultural da região. Além da revitalização, o espaço foi ampliado, foram realizadas instalações cenográficas históricas que celebram a arquitetura dos antigos povos indígenas, agregando valor cultural ao destino turístico.

Figura 2 - Sistema de Fixos Construídos

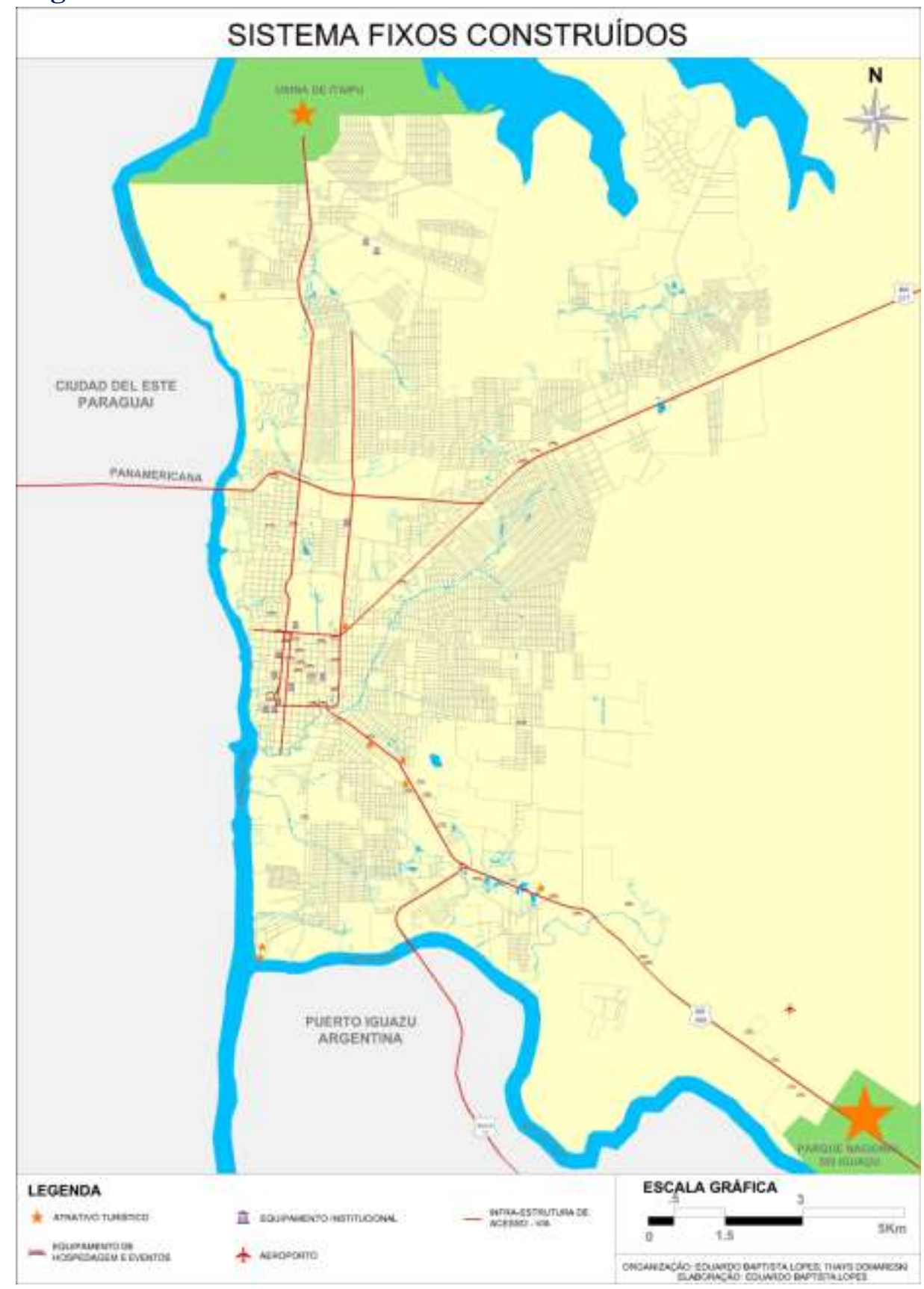

Organização: Eduardo Baptista Lopes; Thays Domareski Ruiz; Elaboração: Eduardo Baptista Lopes.

O sistema de fixos construídos da cidade de Foz do Iguaçu apresenta a diversidade de atrativos que a cidade disponibiliza, além de sua capacidade de acesso considerável, feita por meios rodoviários e aéreos. A exploração dos fixos naturais representados pelos Rios Paraná e Iguaçu através da construção de uma Usina Hidrelétrica (Itaipu) e a criação do PNI evidencia a importância da gestão. No caso da Itaipu a exploração turística surge em segundo plano e se torna juntamente ao PNI os atrativos turísticos mais visitados e mais representativos da cidade. 
Paralelamente, criou-se uma infraestrutura de acesso e serviços de hospedagem para suportar tais atividades.

\subsection{Sistema dos fluxos socioeconômicos}

Os fluxos sociais são estabelecidos pelas dinâmicas socioculturais como: trabalho, lazer, escolaridade, organização política e comportamento social. Os fluxos econômicos compreendem renda, produção, distribuição, consumo e acumulação. Dessa forma, neste capítulo será feita a contextualização do sistema turístico de Foz do Iguaçu sob à ótica dos fluxos socioeconômicos.

De acordo com as estimativas do IBGE (2015), o destino de Foz do Iguaçu conta aproximadamente com uma população de 263.782 habitantes. O quadro de evolução do número de habitantes no município indica que houve um acentuado aumento populacional de 1970 à 2008.

Quadro 2 - Evolução populacional

\begin{tabular}{|c|c|c|}
\hline Data & Período Econômico & Acréscimo Populacional \\
\hline $1870-1970$ & Extração Madeira/Erva-Mate & 33.966 \\
\hline $1970-1980$ & Construção Itaipu Binacional & 102.355 \\
\hline $1980-1995$ & Turismo de Compras & 74.861 \\
\hline $1995-2008$ & Comércio, Turismo de Compras e Eventos & 108.007 \\
\hline
\end{tabular}

Fonte: Inventário de Foz do Iguaçu, 2014.

Uma análise preliminar desses números permite observar que os grandes responsáveis pela configuração atual da população é consequência dos três últimos ciclos econômicos (Construção de Itaipu, Turismo de Compras e Comércio, Turismo de Compras e Eventos), responsáveis pela migração de uma parcela em massa, principalmente evidenciada nos ciclos da construção da Itaipu e do turismo de compras.

Com uma população composta de migrantes, vindos do Brasil e do exterior, Foz do Iguaçu, destaca-se como uma cidade multicultural por abrigar atualmente mais de 70 grupos étnicos, onde a diversidade cultural é um ícone referencial. É considerada uma das cidades mais cosmopolitas do Brasil, dentre os principais grupos étnicos da cidade estão italianos, alemães, argentinos, paraguaios, chineses, japoneses e libaneses, configurando características cosmopolitas ao município.

A cidade de Foz do Iguaçu tem sua economia baseada sobretudo no turismo e na geração de energia elétrica, por meio da construção da Usina Hidrelétrica de Itaipu, iniciada na década de 1970, que impactou toda a região, aumentando consideravelmente a população do município e impactando diretamente no crescimento e desenvolvimento da cidade como um todo. Por outro lado, a exploração do PNI também trouxe investimentos para a cidade, se caracterizando como principal atrativo turístico do destino.

No contexto dos serviços turísticos, o número de agências de turismo, no destino de Foz do Iguaçu é bastante relevante, atualmente com 146 estabelecimentos, que oferecem serviços dos mais diferenciados, desde o receptivo, guias de turismo que falam diversos idiomas e motoristas. 
Quanto ao sistema de hospedagem, a cidade conta com o quarto maior parque hoteleiro ${ }^{12}$ do Brasil e dessa forma, oferece opções para todo perfil de turista, dispõe de estabelecimentos para todas as necessidades e expectativas dos visitantes. Há hotéis com moderna estrutura para eventos e resorts para atividades de lazer e negócios.

Foz do Iguaçu possui também um sistema exclusivo de informações turísticas, que é o TELETUR $^{13}$, que funciona diariamente das $07 \mathrm{~h} 00$ às $23 \mathrm{~h} 30$, e dispõe de informações sobre hospedagem, alimentação e opções de atrativos turísticos da cidade, onde o atendimento é feito em inglês ou espanhol. Além dos cinco postos de informações espalhados pela cidade.

Tabela 1 - Fluxo de Visitantes dos principais atrativos turísticos

\begin{tabular}{c|c|c|c|c|c|c|c|c|c}
\hline Atrativo/Data & $\mathbf{1 9 9 5}$ & $\mathbf{2 0 0 0}$ & $\mathbf{2 0 0 5}$ & $\mathbf{2 0 1 0}$ & $\mathbf{2 0 1 5}$ & $\mathbf{2 0 1 6}$ & $\mathbf{2 0 1 7}$ & $\mathbf{2 0 1 8}$ & $\mathbf{2 0 1 9}$ \\
\hline $\begin{array}{c}\text { Cataratas } \\
\text { do Iguaçu }\end{array}$ & 884.338 & 767.157 & 1.084 .239 & 1.265 .765 & 1.642 .093 & 1.560 .792 & 1.788 .922 & 1.895 .508 & 2.020 .358 \\
\hline $\begin{array}{c}\text { Itaipu } \\
\text { Binacional }\end{array}$ & 472.823 & 459.469 & 670.380 & 496.134 & 822.982 & 955.397 & 979.932 & 1.024 .667 & 1.028 .225 \\
\hline
\end{tabular}

Fonte: IBAMA / ICMBio, Itaipu Binacional, 2019.

Em 2005, as Cataratas do Iguaçu, o principal atrativo turístico do destino, se consolida e atinge pela primeira vez o marco de 1 milhão de turistas. Em 2006, ocorre uma leve queda para 954 mil e a partir de 2007 até 2018 atingem seguidamente a marca de mais de 1 milhão de visitantes no ano. Em 2019 atingem 2 milhões de visitantes, garantindo uma visibilidade e posicionamento maior ao destino. Em 2018, a Itaipu Binacional também atinge a marca de 1 milhão de visitantes. Esses dados são referentes a visitação na margem direita e esquerda, contemplando todas as visitas realizadas pela Itaipu Binacional e os Complexos Turísticos.

O setor turístico de Foz do Iguaçu está bem estruturado com várias entidades do ramo que auxiliam no planejamento e na tomada de decisão de planejamento. Estas instituições colaboram para o desenvolvimento local e regional da tríplice fronteira. No quadro 03, estas instituições foram classificadas em categorias: Binacional, Federal, Regional e Municipal, o que evidencia uma articulação favorável ao desenvolvimento do turismo.

${ }^{12}$ Foz do Iguaçu já ocupou a posição de $4^{\circ}$ maior parque hoteleiro do Brasil em 2011.

${ }^{13}$ Ligação é gratuita, 0800451516. 
Quadro 3 - Instituições de Foz do Iguaçu

\begin{tabular}{|l|c|}
\hline \multicolumn{1}{|c|}{ Instituições } & Categoria \\
\hline PTI - Fundação Parque Tecnológico de Itaipu & Binacional \\
\hline SEBRAE - Serviço de Apoio às Micro e Pequenas Empresas & Federal \\
\hline PRTUR - Paraná Turismo & Regional \\
\hline PÓLO IGUASSU - Instituto Pólo Internacional Iguassu & Regional \\
\hline SMTU - Secretaria Municipal de Turismo & Municipal \\
\hline ICVB - Iguassu Convention \& Visitors Bureau & Municipal \\
\hline FUNDAÇÃO CULTURAL DE FOZ DO IGUAÇU - Fundação Cultural & Municipal \\
\hline COMTUR - Conselho Municipal de Turismo & Municipal \\
\hline ATRIFI - Associação do Receptivo Internacional de Foz do Iguaçu & Municipal \\
\hline SHRBS - Sindicato de Hotéis, Restaurantes, Bares e Similares de Foz do Iguaçu & Municipal \\
\hline SINDETUR - Sindicatos das Empresas de Turismo de Foz do Iguaçu & Municipal \\
\hline SINGTUR - Sindicato dos Guias de Turismo de Foz do Iguaçu & Municipal \\
\hline AGETURFI - Associação de Agências de Viagens e Turismo Receptivo de Foz do Iguaçu & Municipal \\
\hline SECHSFI - Sindicato dos Empregados em Turismo e Hospitalidade de Foz do Iguaçu & Municipal \\
\hline
\end{tabular}

Fonte: Inventário de Foz do Iguaçu, 2019;

Em Foz do Iguaçu, o crescimento urbano e as diretrizes do planejamento são regulamentadas por um Plano Diretor. O plano diretor ${ }^{14}$ é um instrumento da política urbana instituído pela Constituição Federal de 1988, que o define como instrumento básico da política de desenvolvimento e de expansão urbana, e é regulamentado pela Lei Federal n. ${ }^{\circ} 10.257 / 01$, mais conhecida como Estatuto da Cidade, pelo Código Florestal (Lei n. ${ }^{\circ} 4.771 / 65$ ) e pela Lei de Parcelamento do Solo Urbano (Lei n. ${ }^{\circ}$ 6.766/79).

O plano diretor é um documento que sintetiza e torna explícitos os objetivos estabelecendo diretrizes e normas a serem utilizadas como base para que as decisões dos atores envolvidos no processo de desenvolvimento urbano, sejam implementadas no município (Saboya, 2007).

Em Foz do Iguaçu, o Plano Diretor analisado foi o de $2006^{15}$. O Estatuto da Cidade prevê a reformulação do plano em períodos máximos de 10 em 10 anos.

Através da implementação do Plano Diretor de 2006, a prefeitura de Foz do Iguaçu buscou medidas que valorizassem o turismo da cidade, por meio de diretrizes e zoneamento específico, como o incentivo para a implantação de equipamentos voltados ao desenvolvimento turístico, ou que possam responder a essa lógica, como comércios, restaurantes e atividades culturais. Além disso, criou diretrizes que visam a manutenção do patrimônio histórico, a produção artesanal, o desenvolvimento de cooperativas e a capacitação da mão-de-obra voltada ao turismo.

As empresas hoteleiras também receberam incentivos para a implantação de novas unidades em zonas turísticas, bem como no setor de pequenos e grandes eventos, como feiras, seminários, congressos, que podem ser realizados nos espaços dos hotéis.

Com esta proposta, a cidade foi dividida em zonas, dentre elas quatro específicas para o turismo:

- Zona Turística 01 (ZT 01): Essa área localiza-se na Avenida das Cataratas, no trecho já consolidado com forte presença de hotéis. Incentiva as atividades de lazer, como jogos, recreação e cultura, além da inserção de novos serviços de hospedagem com restauração, e espaço para eventos. Esta zona turística corresponde ao Subsistema Turismo-Cataratas, conectando o Centro ao PNI. Durante a vigência do Plano Diretor, entre 2006 e 2016, pode-se

\footnotetext{
${ }^{14}$ Obrigatório para municípios com mais de 20 mil habitantes.
} 
constatar a implantação de novos hotéis, como por exemplo o Hotel Viale, os centros de eventos Espaço Marias, Quinta das Marias e Espaço Papillon, o Shopping Catuaí Palladium e o complexo Dreamland;

- Zona Turística 02 (ZT 02): A Zona Turística 02 representa o outro trecho da Avenida das Cataratas, ainda não consolidado. Tem as mesmas características de uso do solo que a ZT 01, porém é mais permissível em relação aos índices de ocupação. Apesar do incentivo a implantação de novos hotéis, a zona recebeu poucos investimentos no setor hoteleiro;

- Zona Turística 03 (ZT 03): A área engloba a antiga zona verde residencial, nas áreas nobres das margens do rio Paraná e do rio Iguaçu. Incentiva atividades voltadas ao turismo, como serviços de hospedagem, espaços de eventos, serviços de restauração e atividades culturais, desde que não comprometam a imagem da paisagem e garantam a proteção ambiental, já que corresponde a uma zona frágil. Mesmo com legislação permissível, constatou-se poucos investimentos no setor turístico da área;

- Zona Turística 04 (ZT 04): Está localizada em áreas nobres nas margens do rio Iguaçu, possuindo mesmas permissões e restrições quanto ao uso que a ZT 03, contudo com índices de ocupação inferiores.

Além das quatro zonas específicas para o turismo, o Plano Diretor prevê outras quatro zonas que se relacionam diretamente com os subsistemas turísticos:

- Zona de Comércio Central (ZCC): É uma zona de serviços de pequeno a médio porte, ao longo das Avenidas JK, Brasil e Almirante Barroso, e limitadas pelas Avenidas República Argentina e Jorge Schimmelpfeng. É uma área que incentiva o recebimento de investimentos que beneficiem a paisagem urbana, para que tanto moradores quanto turistas vivenciem uma melhor experiência no espaço público. Permite, além disso, verticalização acentuada; Ao longo da vigência do Plano Diretor, esta área central da cidade recebeu diversos investimentos privados, sobremaneira em franquias de alimentação e de comércio, e a implantação do shopping JL Cataratas, em 2007;

- Zona de Comércio de Exportação (ZCE): A Zona de Comércio de Exportação está diretamente ligada ao sistema Turismo - Compras, uma vez que engloba áreas da região da Vila Portes e Jardim Jupira, onde o foco comercial é voltado principalmente para produtos de exportação pela proximidade com a Ponte da Amizade, que faz a ligação Brasil - Paraguai. A aduana entre os dois países, localizada nessa zona, foi revitalizada no ano de 2013. Além disso, a ponte recebeu melhorias de segurança aduaneira, em 2015;

- Zona de Comércio e Serviços 01 (ZCS1): Compreende trechos ao longo da BR-277 e da Avenida Tancredo Neves, e além dos usos pesados, como mecânicas e borracharias, incentiva a inserção de comércios e serviços de alimentação, diversão, cultura e lazer, além de serviços de hospedagem com restauração. Apesar da expansão do Rafain Palace Hotel, nenhum outro equipamento foi implantado na Zona;

- Zona Especial de Proteção (ZEP): Zona de grandes restrições pelo seu caráter ambiental, incentiva o uso controlado para turismo rural.

Além disso, entre 2006 e 2016 diversas ações e melhorias foram executadas no Município, que influenciaram diretamente no desenvolvimento tanto econômico quanto turístico de Foz do Iguaçu. 
Quadro 4 - Ações de impacto direto ao turismo

\begin{tabular}{|c|c|c|c|}
\hline Ação & Local & $\begin{array}{l}\text { Ano do } \\
\text { Projeto }\end{array}$ & $\begin{array}{c}\text { Conclusão da } \\
\text { Obra }\end{array}$ \\
\hline $\begin{array}{l}\text { Reforma do Aeroporto } \\
\text { Internacional de Foz do } \\
\text { Iguaçu }\end{array}$ & Imóvel Cataratas Gleba 3 & 2005 & 2006 \\
\hline $\begin{array}{c}\text { Revitalização da Área } \\
\text { Aduaneira Brasil - Paraguai }\end{array}$ & $\begin{array}{c}\text { Zona primária da Receita } \\
\text { Federal (etapa 1) }\end{array}$ & 2005 & 2006 \\
\hline Feira de Ambulantes & Vila Portes & 2005 & 2005 \\
\hline $\begin{array}{c}\text { Revitalização da Área } \\
\text { Aduaneira Brasil - Argentina }\end{array}$ & $\begin{array}{c}\text { Zona primária da Receita } \\
\text { Federal }\end{array}$ & 2006 & 2006 \\
\hline $\begin{array}{c}\text { Revitalização da Área } \\
\text { Aduaneira Brasil - Paraguai }\end{array}$ & $\begin{array}{c}\text { Zona primária da Receita } \\
\text { Federal (etapa 2) }\end{array}$ & 2007 & 2013 \\
\hline $\begin{array}{l}\text { Reforma do Aeroporto } \\
\text { Internacional de Foz do } \\
\text { Iguaçu }\end{array}$ & Imóvel Cataratas Gleba 3 & 2012 & Outubro/2014 \\
\hline $\begin{array}{l}\text { Construção do viaduto na BR- } \\
277 \text { com a Avenida Paraná }\end{array}$ & Vila A & 2013 & Agosto/2015 \\
\hline $\begin{array}{c}\text { Revitalização da Ponte da } \\
\text { Amizade (BR-277/PR) }\end{array}$ & Ponte da Amizade & Outubro/2014 & 2015 \\
\hline $\begin{array}{l}\text { Prolongamento da Avenida } \\
\text { Andradina }\end{array}$ & Jardim Lancaster II & Janeiro/2016 & Não concluído \\
\hline $\begin{array}{l}\text { Construção de } 14 \text { km de } \\
\text { ciclovias e pavimentação } \\
\text { asfáltica de ruas, em } 35 \\
\text { bairros da cidade }\end{array}$ & $\begin{array}{c}\text { Vila Carimã } \\
\text { Loteamento Bubas } \\
\text { Profilurb } \\
\text { Jardim Tropical } \\
\text { Parque Residencial Ouro Verde } \\
\text { Jardim Bourbon } \\
\text { Jardim Residencial São Roque } \\
\text { Loteamento Cataratas } \\
\text { Loteamento Sohab } \\
\text { Jardim Central } \\
\text { Jardim Polo Centro } \\
\text { Parque Presidente I } \\
\text { Portal da Foz } \\
\text { Loteamento Campos do Iguaçu } \\
\text { Jardim Terra e Lar } \\
\text { Jardim Manaus } \\
\text { Jardim Panorama } \\
\text { Jardim Maracanã } \\
\text { Jardim Claudia } \\
\text { Jardim São Paulo } \\
\text { Jardim Acaray } \\
\text { Conjunto Residencial Libra } \\
\text { Parque Residencial Morumbi } \\
\text { Vila Borges } \\
\text { Vila C Velha } \\
\text { Vila São Sebastião }\end{array}$ & Abril/2016 & Não concluído \\
\hline
\end{tabular}

Fonte: Material elaborado com base nas informações disponibilizadas pela Secretaria de Planejamento Urbano e de Turismo de Foz do Iguaçu, 2015.

É possível perceber o fortalecimento de todos os serviços turísticos ao longo da Avenida das Cataratas, local onde o plano diretor prevê o desenvolvimento de áreas ainda não consolidadas, mas que possuem potencial de desenvolvimento turístico. A Avenida das Cataratas possui infraestrutura específica, e desenvolveu mais alguns atrativos ao longo de seu percurso. Porém, a população cobra sua duplicação e melhorias na sinalização e paisagismo, 
por ser o corredor turístico do destino. O Aeroporto Internacional de Foz do Iguaçu teve obras de revitalização em 2013, porém, não foram suficientes para acompanhar o aumento de fluxo de turistas no destino. Desde 2018, o terminal do aeroporto passa por obras de expansão e revitalização nas áreas de check-in, salas de embarque e saguão, além da instalação de quatro pontes de embarque e desembarque. A reforma também prevê alteração do layout do aeroporto e a criação de novos pontos comerciais e de publicidade, realizados pelo Fundo Iguassu em parceria com a Infraero.

Essas características reforçam o caráter de sua área parcialmente ocupada, que também pode receber investimentos para sua consolidação. Além disso, a revitalização de zonas já consolidadas, como em bairros comerciais e de serviços, busca melhorar a imagem da cidade enquanto destino turístico, uma vez que cria espaços públicos mais agradáveis e convidativos tanto para moradores quanto para turistas. Essas ações da esfera pública demonstram suas claras intenções em incentivar o turismo no destino.

A ampliação do aeroporto internacional, além da reforma na área existente oferece maior conforto e uma gama mais ampla de serviços aos usuários.

A revitalização do entorno da Ponte Internacional da Amizade, que proporciona maior conforto e segurança, uma vez que organiza e agiliza o fluxo na ponte, bem como melhora a imagem das cidades tanto para moradores quanto para visitantes. Dentre as obras, a construção de novos centros de recepção de visitantes e pistas exclusivas. Outra intervenção importante foi a revitalização da área aduaneira Brasil-Argentina, através de projetos paisagísticos que ordenam o fluxo e aumentam a segurança em relação ao contrabando de mercadorias.

Não menos importante, as ações de aprimoramento no sistema viário fortalecem a mobilidade tanto de turistas quanto de residentes, apresentando impacto direto no turismo.

\section{Considerações finais}

O turismo no destino de Foz do Iguaçu deve ser analisado como fator de desenvolvimento e crescimento da cidade. É possível observar que o setor econômico da geração de energia elétrica e o do turismo foram fundamentais no processo de desenvolvimento local. Os dois setores desempenharam papéis determinantes, sejam sociais, econômicos, culturais e ambientais, sem necessariamente uma igualdade em efeitos. No entanto, se observados isoladamente, são perceptíveis os impactos em todas essas ordens (Domareski, 2011). Neste sentido, as políticas são determinadas pelo setor público e devem estar condicionadas por características econômicas, sociais e culturais da sociedade local, bem como pelas estruturas formais do governo e do sistema político (Montejano, 1999; Hall, 2004; Lickorish e Jenkins, 1997; Beni, 2006; Rabahy, 2003).

É necessário evidenciar que há um eixo que ordena os impactos do desenvolvimento econômico de Foz do Iguaçu, baseado nos recursos naturais, devidamente centrados na exploração do $\mathrm{PNI}^{16}$, onde são localizadas as Cataratas do Iguaçu e demais atrativos turísticos que se formaram na visão "mercadológica" do PNI, além da própria exploração turística na Hidrelétrica de Itaipu. Todo esse processo resultou em um aumento de fluxo turístico no local, que como consequência, provocou uma gestão e administração mais eficaz dos fixos naturais, além de incentivos específicos nos fixos construídos.

Além disso, a revitalização de zonas já consolidadas da cidade busca a melhora da imagem da cidade enquanto destino turístico, demonstrando o cuidado do Estado em apresentar a cidade e incentivar o turismo de compras.

16 Tombado como Patrimônio Natural da Humanidade e onde estão localizadas as Cataratas do Iguaçu. 
Os impactos positivos do turismo sobre o desenvolvimento econômico podem ser observados através do aumento da renda do lugar visitado via entrada de divisas, onde há estímulo nos investimentos, que acabam por gerar empregos e auxiliam na redistribuição de renda. Com essa realidade, as mudanças mencionadas anteriormente nas percepções públicas do turismo como um setor principal da economia do destino, levaram a atividade turística ao centro das atenções globais (Domareski-Ruiz \& Anjos; 2013).

As políticas públicas, observadas no plano diretor, para o processo de produção do espaço turístico da cidade evidenciam o crescimento de equipamentos voltados ao turismo, ou que possam responder a essa lógica, como comércios, restaurantes e atividades culturais. Diversas zonas tem como foco principal a regulação das atividades turísticas, através da atribuição de áreas próprias para implantação de equipamentos de hospedagem, restauração e lazer. Os investimentos e equipamentos turísticos tem um reflexo direto no aumento do fluxo turístico local, que vem a beneficiar toda a região da tríplice fronteira.

O Plano Diretor de Foz do Iguaçu é fundamental para o desenvolvimento do turismo na cidade, sobretudo da Avenida das Cataratas. Entende-se, contudo, que a continuidade desse desenvolvimento perpassa pela manutenção ou até mesmo pela ampliação dos incentivos públicos, através de índices mais permissíveis, ou de ações conjuntas do Planejamento Urbano e do Planejamento Turístico do município.

A pesquisa também demonstrou projetos pontuais que contribuíram diretamente na venda da imagem das cidades que compõem a tríplice fronteira, como as revitalizações nas áreas aduaneiras de Brasil - Argentina e de Brasil - Paraguai, que beneficiam a articulação e organização dos fluxos e também promovem o aumento da segurança, estimulando o crescimento das trocas sociais.

No caso de Foz do Iguaçu, o Plano Diretor evidenciou áreas e zonas de interesse para o turismo, contribuindo diretamente para o gerenciamento do Subsistema Turismo-Compras e de Subsistema Turismo-Cataratas na ampliação de atrativos turísticos da cidade, configurando o desenvolvimento do turismo na cidade.

\section{Referências}

Anjos, F. A. dos. (2004). Processo de Planejamento e Gestão de Territórios Turísticos: uma proposta sistêmica. (Tese de Doutorado, apresentado ao programa de pós-graduação em Engenharia de Produção). Universidade Federal de Santa Catarina. Florianópolis, SC.

Anjos, F. A. dos.; Anjos, S. J. G. dos.; Oliveira, J. P. (2013). A abordagem sistêmica no processo de planejamento e gestão de territórios urbanos turísticos. Rosa dos Ventos Turismo e Hospitalidade, 5(3).

Barros, A. J. S.; Lehfeld, N. A. S. (2000). Fundamentos de Metodologia: Um Guia para a Iniciação Científica. 2 Ed. São Paulo, SP: Makron Books.

Beni, M. C. (2006). Política e Planejamento de Turismo no Brasil. São Paulo, SP: Aleph.

Brasil. (2002). Estatuto da Cidade: guia para implementação pelos municípios e cidadãos. 2 ed. Brasília, DF: Câmara dos Deputados, Coordenação de Publicações.

Bruyne, P.; Herman, J.; Schoutheete, M. (1977). Dinâmica da pesquisa em ciências sociais: os pólos da prática metodológica. Rio de Janeiro: F. Alves, 251 p. 
Cervo, A. L.; Bervian, P. A.; Silva, R. da. (2007). Metodologia Científica. 6. ed. São Paulo, SP: Person Prentice Hall.

Chen, L.; Thapa, B.; Kim, J.; Yi, L. (2017). Landscape Optimization in a Highly Urbanized Tourism Destination: An Integrated Approach in Nanjing, China. Sustainability. (9), 1-20.

Crouch, G. I.; Ritchie, J. R. B. (1999). Tourism, Competitiveness, and Societal Prosperity. Journal of Business Research, 44, (3), 137-152.

Cruz, R. C. (2000). Política de Turismo e Território. São Paulo, SP: Contexto.

Dias, R. (2003). Planejamento do Turismo: Politica e Desenvolvimento do Turismo no Brasil. São Paulo, SP: Atlas.

Domareski-Ruiz, T. C. (2011). A Competitividade das Destinações Turísticas: O Caso de Foz do Iguaçu (Pr), Brasil. (Dissertação apresentada no Mestrado em Turismo e Hotelaria). Universidade do Vale do Itajaí. Balneário Camboriú, SC.

Domareski-Ruiz, T. C.; Anjos, F. A. dos.; Anjos, S. J. G. dos. (2013). Competitividad de Destinos Turísticos. Estudio de Caso de Foz do Iguaçu (Paraná, Brasil). Cuadernos de Turismo, 31, 83-103.

Foz do Iguaçu, Prefeitura Municipal de Foz do Iguaçu. (2015). Disponível em: $<$ http://www.fozdoiguacu.pr.gov.br>.

Gandin, D. (2001). Posição do planejamento participativo entre as ferramentas de intervenção na realidade. Currículo sem Fronteira, 1, (1), 81-95.

Godoy, A. S. (1995). Introdução à pesquisa qualitativa e suas possibilidades. Revista de Administração de Empresas, 35, (2), 57-63.

Hall, C. M. (2001). Planejamento Turístico: políticas, processos e planejamentos, São Paulo, SP: Contexto.

Hankinson, G. (2010). Place branding research: A cross-disciplinary agenda and the views of practitioners, Place Branding and Public Diplomacy, Vol. 6, 4, pp. 300-315.

IBGE. (n.d.). Instituto Brasileiro de Geografia e Estatística. Disponível em: $<$ http://www.ibge.gov.br>.

Lickorish, L. J.; Jenkins, C. L. (2000). Introdução ao Turismo. Trad. Fabíola de Carvalho S. Vasconcellos. Rio de Janeiro, RJ: Campus.

Lohmann, G.; Panosso Netto, A. (2008). Teoria do Turismo: Conceitos, modelos e sistemas (pp. 121-144). São Paulo, SP: Aleph.

Machado, P. A. L. (2012). Direito ambiental brasileiro. 20 ed. São Paulo, SP: Malheiros. 
Mccartney, G. (2008). The CAT (casino tourism) and the MICE (meetings, incentives, conventions, exhibitions): Key development considerations for the convention and exhibition industry in Macao. Journal of Convention \& Event Tourism, 9, (4), 293-308.

Malhotra, N. K. (2006). Pesquisa de Marketing: uma orientação aplicada. 4. ed. Porto Alegre, RS: Bookman.

Montejano, J. M. (1999). Estructura del mercado turístico: gestión turística. Madrid: Síntesis.

Munhoz, D. G. (1989). Economia Aplicada. Técnicas de pesquisa e Análise Econômica. Brasília, DF: Editora de Brasília.

OMT. (2015). Organização Mundial do Turismo. Disponível em: <http://www.unwto.org/facts/eng/vision.htm>.

Pearce, D. G. (2016). Modelos de Gestión de Destinos. Estudios y Perspectivas en Turismo, $15,1-16$.

PDMFOZ. Plano Municipal de Foz do Iguaçu. Prefeitura Municipal de foz do Iguaçu, 2006.

Rabahy. W. A. (2003). Turismo e desenvolvimento: estudos econômicos e estatísticos no planejamento. 1. ed. Barueri, SP: Manole.

Rezende, D. A.; Ultramari, C. (2007). Plano diretor e planejamento estratégico municipal: introdução teórico-conceitual. Revista de Administração Pública, 41, (2), 255-271.

Richardson, R. J. (1999). Pesquisa Social: Métodos e Técnicas. São Paulo, SP: Atlas.

Ruschmann, D. (1997). Turismo e desenvolvimento sustentável: a proteção do meio ambiente. Campinas, SP: Papirus.

Saboya, R. (2007). Concepção de um sistema de suporte à elaboração de planos diretores participativos. (Tese de Doutorado apresentada ao Curso de Pós-Graduação em Engenharia Civil). Universidade Federal de Santa Catarina. Florianópolis. SC.

Pearce, D. G.; Schänzel, H. A. (2013). Destination management: The tourists' perspective. Journal of Destination Marketing \& Management, 2, (3), 137-145.

Saraniemi, S.; Kylanen, M. (2011). Problematizing the concept of tourism destination: An analysis of different theoretical approaches. Journal of Travel Research. 50, (2), 133-143.

Santos, M. (1997). A natureza do espaço. 2.ed. São Paulo, SP: Hucitec.

Vieira, A. R. M. (2011). Planejamento e políticas públicas de turismo: análise dos módulos operacionais do Programa de Regionalização do Turismo no Polo São Luís-MA.

(Dissertação apresentada ao Mestrado de Turismo) Universidade de Brasília, Brasília, DF.

Yin. R. K. (2005). Estudo de caso: planejamento e métodos. 3 ed. Porto Alegre: Bookman. 